\title{
Life-threatening gastrointestinal bleeding in Klippel-Trenaunay syndrome
}

\begin{abstract}
A 28-year-old Hispanic man was brought to the hospital by emergency medical services after several hours of passing bright red blood per rectum. He complained of feeling dizzy and at the emergency center, he continued to pass a large amount of bright red blood per rectum. On admission his hemoglobin was $6.0 \mathrm{~g} / \mathrm{dL}$. He had a similar episode of bleeding at age 16 , which stopped spontaneously and no further investigation was done at that time. On examination, he had extensive varicose veins and hypertrophy of the left lower extremity ( $\bullet$ Fig. 1). He reported that these varicose veins were first noticed in early infancy. Colonoscopy showed extensive varicosities with bluish discoloration throughout the rectum and

\section{Competing interests: None}

\section{N. Thosani ${ }^{1,2}$, Y. Ghouri ${ }^{2}$, S. Shah ${ }^{3}$, S. Reddy ${ }^{1,2}$, G. Arora ${ }^{1,2}$, L. D. Scott ${ }^{1,2,4}$}

${ }^{1}$ Department of Internal Medicine, University of Texas Health Science Center at Houston, Texas, United States of America ${ }^{2}$ Division of Gastroenterology, Hepatology and Nutrition, University of Texas Health Science Center at Houston, Texas, United States of America

${ }^{3}$ Department of Radiology, University of Texas Health Science Center at Houston, Texas, United States of America

${ }^{4}$ Lyndon B. Johnson Hospital, Harris County Hospital District, Houston, Texas, United States of America
\end{abstract} sigmoid colon ( $\bullet$ Fig. 2 ) and large hemorrhoids. He had emergent hemorrhoidectomy to control bleeding. Based on the physical examination findings, he was diagnosed as having Klippel-Trenaunay syndrome (KTS). At 2-year follow-up, he continues to do well without any further episodes of bleeding.

KTS is a rare congenital disorder with variable clinical presentation related to malformations of blood and lymph vessels, and disturbed growth of bone and soft tissue. It is usually characterized by a triad of a localized vascular nevus, congenital or early infantile varicosities on the same body part, and hypertrophy of tissues on that body part [1]. Life-threatening gastrointestinal bleeding due to diffuse cavernous hemangiomas has been reported in an estimated $1 \%-12.5 \%$ of KTS cases [2]. The most common site of involvement is the rectum or rectosigmoid colon [2]. However, involvement of esophagus, stomach, and small intestine has also been reported [2]. Radiological investigations and endoscopy complement each other in assessing the colorectal involvement in KTS and in identifying the specific bleeding site [3]. Gastrointestinal bleeding in KTS can be life threatening; thus, awareness of this rare condition can facilitate appropriate management.

Endoscopy_UCTN_Code_CCL_1AD_2AF

\section{References}

1 Oduber CE, van der Horst CM, Hennekam RC. Klippel-Trenaunay syndrome: diagnostic criteria and hypothesis on etiology. Ann Plast Surg 2008; 60: 217-223

2 Wilson CL, Song LM, Chua $H$ et al. Bleeding from cavernous angiomatosis of the rectum in Klippel-Trenaunay syndrome: report of three cases and literature review. Am J Gastroenterol 2001; 96: 2783-2788

3 Wang ZK, Wang FY, Zhu RM et al. KlippelTrenaunay syndrome with gastrointestinal bleeding, splenic hemangiomas and left inferior vena cava. World J Gastroenterol 2010; 16: $1548-1552$

\section{Bibliography}

Dol http://dx.doi.org/

10.1055/s-0032-1326645

Endoscopy 2013; 45: E206

(c) Georg Thieme Verlag KG

Stuttgart · New York

ISSN 0013-726X

\section{Corresponding author}

\section{N. Thosani}

Department of Gastroenterology, Hepatology, and Nutrition

MSB 4.234, 6410 Fannin

University of Texas Medical School at Houston Houston

TX 77030

USA

Fax: +1-713-5006699

in2104@poh.osaka-med.ac.jp

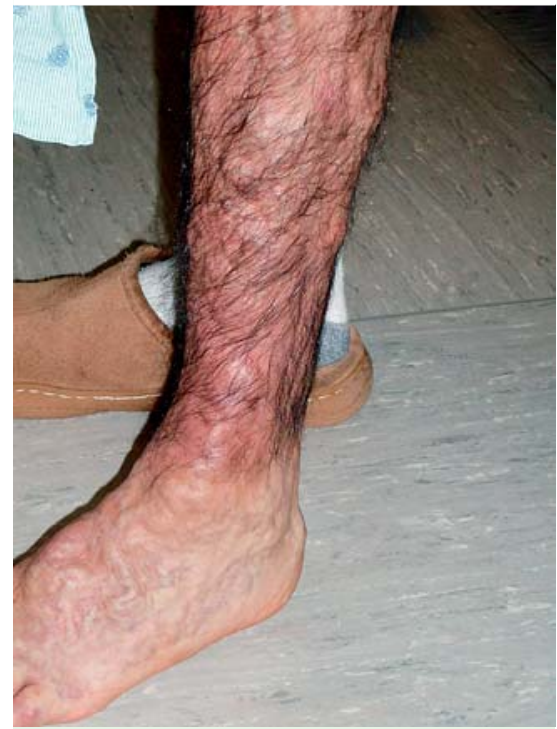

Fig. 1 Extensive varicose veins (unilateral) in left lower extremity of a 28-year-old Hispanic man passing bright red blood per rectum.

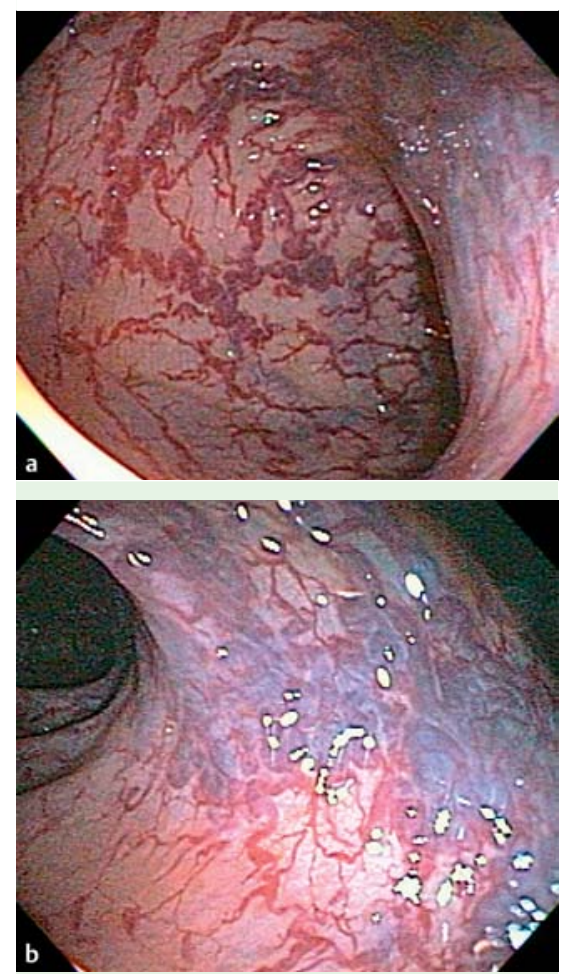

Fig.2 Extensive varicosities with bluish discoloration in a rectum and $\mathbf{b}$ rectosigmoid colon. 